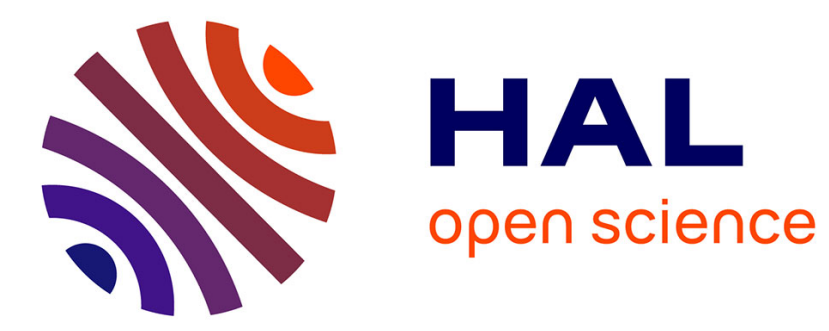

\title{
Using hydraulic equivalences to discriminate transport processes of volcanic flows.
}

\author{
Alain Burgisser, James E. Gardner
}

\section{To cite this version:}

Alain Burgisser, James E. Gardner. Using hydraulic equivalences to discriminate transport processes of volcanic flows.. Geology, 2006, 34, No. 3, pp. 157-160. 10.1130/G21942.1 . hal-00022571

\section{HAL Id: hal-00022571 \\ https://hal-insu.archives-ouvertes.fr/hal-00022571}

Submitted on 11 Apr 2006

HAL is a multi-disciplinary open access archive for the deposit and dissemination of scientific research documents, whether they are published or not. The documents may come from teaching and research institutions in France or abroad, or from public or private research centers.
L'archive ouverte pluridisciplinaire HAL, est destinée au dépôt et à la diffusion de documents scientifiques de niveau recherche, publiés ou non, émanant des établissements d'enseignement et de recherche français ou étrangers, des laboratoires publics ou privés. 


\section{Using hydraulic equivalences to discriminate transport processes}

\section{2 of volcanic flows ${ }^{1}$}

3 Alain Burgisser

4 Institut des Sciences de la Terre d'Orléans, CNRS - Université d'Orléans, 45071 Orléans,

5 France

6 James E. Gardner

7 Department of Geological Sciences, University of Texas at Austin

$8 \quad$ Austin, Texas 78712-0254, USA

9 ABSTRACT

10 We characterized stratified deposits from Upper Toluca Pumice at Toluca Volcano,

11 Mexico, to distinguish the various modes of transport at play in their genesis. Using the concept

12 of hydraulic equivalence, we determined that deposits resulted from a combination of suspended-

13 load fallout, saltation, and rolling. In particular, some well-sorted coarse stratified beds have a

14 single pumice mode most likely indicative of clasts having traveled through both the transport

15 system and the traction bed. Such beds are likely remnants of the sorting operated within the

16 large-scale transport system. Other coarse beds have pumice and lithic modes suggesting rolling

17 in the traction bed. We propose that boundary layer processes control the sorting of those beds

18 and all finer beds. By helping to discriminate between transport mechanisms, hydraulic

19 equivalences have a general applicability in geophysical flows involving clasts of contrasted

20 densities.

21 Keywords: hydraulic equivalence, stratified deposit, sedimentation, volcanic eruption, surge.

\footnotetext{
${ }^{1}$ GSA Data Repository item 2005\#\#, stratigraphic logs, field photographs, and sedimentological analysis, is available online at www.geosocitey.org/pubs/ft2005.htm, or on request from editing@geosociety.org or Documents Secretary, GSA, PO Box 9140, Boulder, CO 80301-9140, USA.
} 


\section{INTRODUCTION}

Nearly all volcanoes feature stratified pyroclastic deposits composed of well to

25 moderately sorted cross- and planar beds (e.g., Cas and Wright, 1987). Despite the ubiquity of

26 such deposits, we only have a crude understanding of their genesis. Moreover, stratified deposits

27 often record superimposed origins, because fall and pyroclastic density currents are only end-

28 members of a continuum of volcanic flows (Wilson and Hildreth, 1998). Distinguishing between

29 the various modes of transport at play is a necessary step toward accessing crucial information

30 about the parent flow and the associated eruptive regime.

31 In an attempt to discriminate transport processes, we review and develop the concept of

32 hydraulic equivalence, which states under what conditions clasts of various sizes and densities

33 are similarly transported. This method is then applied to grain-size data from stratified deposits

34 that are part of the Upper Toluca Pumice (UTP) at Nevado de Toluca Volcano, Mexico (Fig. 1).

\section{HYDRAULIC EQUIVALENCES}

36 Models of volcanic flows invoke several processes of sedimentation that generate

37 stratified deposits, including suspended-load fallout, saltation, rolling and gravity grain flow

38 (Wohletz and Sheridan, 1979; Fisher, 1990; Valentine, 1987; Sohn, 1997). We disregard gravity

39 grain flow as a process occurring in most pyroclastic stratified deposits because cross-beds

40 almost always dip less steeply than the angle of repose. We propose to discriminate between the

41 remaining three mechanisms through their potential for sorting particles by size and density. In

42 each case, hydraulic equivalence is reached when particles (pumice and lithics) have a similar

43 (usually steady-state) motion. 
Suspended-load fallout occurs when particles that are carried mainly by large-scale

45 turbulent motions of hot gases sediment from the pyroclastic cloud (Valentine, 1987). Clasts fall

46 at their terminal fall velocity $\left(U_{T}\right)$, which is given by (Crowe et al., 1997):

47

$$
\begin{aligned}
& U_{T}=\frac{4 \rho d^{2} g}{3 \mu C_{D} \operatorname{Re}}(1 \mathrm{a}) \\
& C_{D}=\frac{24}{\operatorname{Re}}+\frac{3.6}{\operatorname{Re}^{0.313}}+\frac{0.42}{\operatorname{Re}+42500 R e^{-0.16}}, \operatorname{Re}<10^{5}
\end{aligned}
$$

49 where $\rho$ is clast density, $d$ is clast diameter, $\mu$ is (dusty) gas viscosity, $R e$ is particle Reynolds 50 number $\left(=U_{T} d / v\right), v$ is kinematic viscosity of the (dusty) gas, $g$ is gravity acceleration, and $C_{D}$ is

51 a drag coefficient. Hydraulic equivalence for fallout (including from suspension) is reached

52 when pumice of density $\rho_{l}$ and size $d_{l}$ have the same terminal velocity as lithics of density $\rho_{2}$

53 and size $d_{2}$ (Fig. 5b). We use hot air $\left(\mu=1.510^{-5} \mathrm{~Pa} \mathrm{~s}, v=310^{-5} \mathrm{~m}^{2} / \mathrm{s}\right)$ in this study, noting

54 equivalences are little affected by values of $\mu$ and $v$. Analytical solutions of (1) can be found

55 using $C_{D}=24 / \operatorname{Re}$ for Stokes flow and $C_{D} \sim 0.45$ at large $R e$ :

$$
\rho_{1} d_{1}^{2} \cong \rho_{2} d_{2}^{2} \text { for } \operatorname{Re}<10(2 \mathrm{a})
$$

$$
\rho_{1} d_{1} \cong \rho_{2} d_{2} \text { for } \operatorname{Re}>10^{3}(2 \mathrm{~b})
$$

At low $R e$, lithics fall at the same speed as pumice that are $\sim \sqrt{\rho_{2} / \rho_{1}}$ larger, whereas at high $\operatorname{Re}$,

59 lithics fall at the same speed as pumices that are $\rho_{2} / \rho_{1}$ larger. Hence, suspended-load fallout sorts

60 clasts as a function of both size and density, with more marked sorting for larger clasts.

61 Clasts may saltate steadily if the current supplies enough energy to balance that lost

62 during bouncing. Considering that clasts usually reach their terminal fall velocity before impact

63 (Hanes and Bowen, 1985), the airborne part of the motion sorts between clasts according to (1)-

64 (2). To what extent, however, repeated bouncing, which is confined to a short part of the motion, 
65 affects sorting? Typically, bouncing clasts keep between 20 and $60 \%$ of their kinetic energy, 10

$6640 \%$ of which is rotational. The total kinetic energy of a steadily saltating clast before impact is

67 thus (Chau et al., 2002):

$68 \quad E_{k}=A \frac{\pi}{12} d^{3} \rho U_{T}^{2}$

69 where $A$ is a coefficient between 1.1 and 1.4 taking account of rotation. Hydraulic equivalence

70 for the conserved part of the kinetic energy occurs when, at equivalent velocity before impact,

71 clasts lose the same amount of energy during rebound:

72

$$
\rho_{1} d_{1}^{3}=\rho_{2} d_{2}^{3}(4)
$$

73 The scatter of experimental data (Chau et al., 2002; Cagnoli and Manga, 2003) suggests rebound

74 angle, clast shape, and the nature of the surface may exert a greater control on the amount of

75 energy dissipated during rebound than the difference in material properties between pumice and

76 lithics (i.e., strength and density). One can nevertheless expect that pumices deform and/or break

77 more easily than lithics, which compensates somewhat the equivalence in (4) by allowing lithics

78 to conserve a higher kinetic energy than pumice, all other parameters being equal. Thus, despite

79 pumices slowing down more markedly than lithics during rebound, the airborne trajectory tend to

80 dominate the way saltation segregates clasts.

81 Clasts rolling down freely a rough surface made of identical particles can reach constant

82 velocity depending on the inclination of the surface. The total kinetic energy of a rolling clast is

83 (Dippel et al., 1996):

84

$$
E_{k}=\frac{7 \pi}{60} \rho d^{3} v_{t}^{2}
$$


85 where $v_{t}$ is tangential velocity. As a clast rolls from one bed particle to the next, it loses speed

86 because of the sharp change in direction. By energy balance, tangential speeds before $\left(v_{i}\right)$ and

87 after $\left(v_{f}\right)$ the collision are related by (Dippel et al., 1996):

$$
v_{f}=v_{i} \sqrt{1-\frac{20}{7} \frac{\lambda^{2} d(d+2 \lambda)}{(d+\lambda)^{4}}}
$$

where $\lambda$ is diameter of bed particles. To maintain steady-state rolling on a horizontal surface, we

90 propose that the loss in kinetic energy from one bed particle to the next must be balanced by the

91 work done by a external force $F_{t}$ over the length of a bed particle diameter:

$$
\lambda F_{t}=\frac{\pi}{3} \rho d^{4} \lambda^{2} v_{i}^{2} \frac{(d+2 \lambda)}{(d+\lambda)^{4}}(7)
$$

93 We consider for now that $F_{t}$ is some average force $\left(F_{t} \sim \rho^{m} d^{n}\right)$ that the current steadily applies

94 on the rolling clasts. Using (5)-(7), hydraulic equivalence for steady-state rolling becomes:

$$
\rho_{1}^{(1-m)} d_{1}^{(4-n)} \frac{\left(d_{1}+2 \lambda\right)}{\left(d_{1}+\lambda\right)^{4}}=\rho_{2}^{(1-m)} d_{2}^{(4-n)} \frac{\left(d_{2}+\lambda\right)}{\left(d_{2}+\lambda\right)^{4}}
$$

If $F_{t}$ is related to the shear applied by the air/dusty gas, it likely depends on both size and density

$97(m \rightarrow 1, n>0)$, and hydraulic equivalence is only ensured for clasts of identical sizes. On the other

98 hand, if $F_{t}$ is mostly due to closely-spaced impacts from other moving particles, like under

99 packed conditions, it may be independent of size and density $(m, n=0)$. The equivalence $\left(d_{1} / d_{2}\right)$

100 varies then from $\left(\rho_{2} / \rho_{1}\right)^{0.4}$ to $\rho_{2} / \rho_{1}$ as the substratum change from rough $\left(\lambda=d_{1}\right)$ to smooth

$101 \lambda\left(\lambda=d_{1} / 1000\right)$, respectively, and sorting is similar to that of airborne transport. If rolling is

102 triggered by an impulsive force, such as infrequent collisions, $F_{t}$ cannot be averaged. Instead,

103 clasts are suddenly accelerated and roll freely on the rough surface until the next impulse.

104 Rolling is then a sole function (Dippel et al., 1996) of the initial angular velocity $\left(v_{\phi}\right)$, which is 
105 related to the impulsive tangential force $\left(F_{i}\right)$ applied to the clast surface by (Schmeeckle and

106 Nelson, 2003):

107

$$
F_{i}=\frac{\pi}{15} \rho d^{4} \frac{d v_{\phi}}{d t}(9)
$$

108 Hydraulic equivalence of impulsive rolling is reached when a given impulse leads to a similar 109 angular acceleration for both particles:

$$
\rho_{1} d_{1}^{4}=\rho_{2} d_{2}^{4}(10)
$$

111 Thus, lithics would roll along with pumices that are $\sqrt[4]{\rho_{2} / \rho_{1}}$ larger. Hence, rolling sorts clasts

112 mostly by size and only weakly by density compared to fallout and saltation, except when caused

113 by a force independent of clast size and density.

114 Our analysis shows saltation, fallout, and packed rolling cannot be discriminated solely

115 on the basis of sorting and will thus be considered together. Shear- and collision-induced rolling,

116 however, can be discriminated from the other mechanisms if pumice densities differ greatly from

117 lithic densities and have a restricted range. This is the case at Toluca, where a Kolmogorov-

118 Smirnov test with densities measured at UTP shows that sorting differences are statistically

119 significant even for small grain sizes.

\section{STRATIFIED DEPOSITS OF THE UTP}

121 The most recent Plinian eruption of Toluca volcano produced the $10445 \pm 95$ B.P. dacitic

122 UTP (Arce et al., 2003), which consists of four successive Plinian fall units $\left(\mathrm{PC}_{0}-\mathrm{PC}_{3}\right)$

123 interlayered with three pyroclastic density current units $\left(\mathrm{F}_{0}-\mathrm{F}_{2}\right)$. Our focus is on the better-

124 preserved pyroclastic unit, $F_{1}$, which is composed of a Basal unit that has mainly stratified layers, 125 a well sorted Middle unit, and a Top unit (Fig. 1). The Middle unit has characteristics typical of 126 fall deposits mixed with some products of pyroclastic current (relevant data supporting this 
127 interpretation are in the electronic supplement). Overall, thinner parts of the Top unit tend to be

128 on paleo-highs and feature stratified layers, whereas thicker parts fill paleovalleys and generally

129 consist of multiple massive, poorly sorted subunits. At some locations, pumice levees and paleo-

130 gullies indicate that the flow was channeled. These flow lines mostly follow the general slope of

131 the topography, from the vent down to the surrounding plain. Massive units can be traced

132 laterally into stratified layers and, in one exposed area, a massive unit merges downstream into

133 stratified unit (Fig. 2).

134 We made representative samplings of the stratified deposit by collecting 9 individual

135 beds at 4 locations and 12 bulk samples at 8 locations (Fig. 1, see electronic supplement for

136 detailed description). Six of these 21 samples were from the Basal unit, the others being from the

137 Top unit. We collected 6 representative samples from massive deposits in the Top unit. We also

138 measured the downstream wavelength and amplitude of 39 dunes, and the downstream length

139 and thickness of 14 planar beds (Fig. 3).

140 Stratified layers are composed of, on average, $36 \mathrm{wt} . \%$ angular to poorly rounded

141 pumice, 26 wt. $\%$ angular lithics, $23 \mathrm{wt} . \%$ crystals, and $15 \mathrm{wt} . \%$ glass. They have no systematic

142 vertical or horizontal trend in pumice-to-lithic ratio, and the stratification angle of cross-beds is

143 always $<20^{\circ}$. Bulk samples of stratified layers are poorly sorted and polymodal, with modes

144 around $-3.5 \phi,-1.5 \phi$, and $2 \phi$ (Fig. 4a). Individual beds, in contrast, are moderately to well-

145 sorted with size distributions dominated by one of the modes of the bulk deposit (Fig. 4b).

146 Density sorting of the modes is similar for all grain sizes, except for the coarsest modes of some

147 samples, which are richer in pumice (Fig. 4c). This double sorting of sizes and densities can be

148 seen in the field because well-sorted layers of coarse pumice are easily distinguished from finer

149 layers of mixed clasts. These coarse layers are common, although less abundant than finer beds. 
150 They contain either subordinate lithics with sizes similar to those of pumices, or very few lithics

151 with ill-defined modes (Fig. 5a). Interestingly, coarse lithic-rich beds are absent. Coarser planar

152 beds are thicker and more extensive than finer planar beds (Fig. 3), and they often develop

153 downstream from an oversized clast. Dune-forms consist of stacked cross-beds that often built

154 around a small irregularity of the substratum. Like planar beds, height and length of dunes are

155 related by a power law (Fig. 3). There is no relationship between dune size and distance from 156 vent.

157 We analyzed samples from a transitional zone where a poorly-sorted massive deposit 158 grades downstream over a distance of $10 \mathrm{~m}$ into sub-horizontal beddings that are either massive 159 or well-sorted in coarser clasts (Fig. 2a). No sorting occurs between the massive deposit and the 160 massive beds; samples are indistinguishable (Fig. 2b-c). When comparing the massive deposit

161 with coarse beds, we note that little density sorting occurs (Fig. 2c). Coarse beds are thus evenly 162 depleted in finer sizes compared to the neighboring massive deposit, and have one dominant 163 mode of pumice and lithics, respectively (ATO128, Fig. 5a).

164 DISCUSSION

165 We used the lithic and pumice modes from a sample of the fall deposit $\mathrm{PC}_{2}$ to verify the 166 hydraulic equivalence we determined for fallout (Fig. 5). The magnitude of the error suggests 167 grain size distributions determined at $1 \phi$ intervals, like that of $\mathrm{PC}_{2}$, poorly resolve pumice and 168 lithic modes. Half $\phi$ intervals, like those of the other samples, are necessary to resolve hydraulic 169 equivalences.

170 The presence of a mixed fall layer suggests the Top and Basal units were emplaced by

171 two short partial collapses of an eruptive column. The absence of systematic component

172 gradation within the stratified layers of these units precludes that inter-bed variations were 
173 caused by fluctuations of component proportion at the vent. Hence, all sedimentological

174 variations resulted instead from transport or sedimentary processes.

175 Sorting in the UTP stratified deposits is best expressed in the coarser beds. Some coarse

176 beds have similar modes of pumice and lithic (ATO7, Fig. 5a), which suggest they deposited by

177 rolling (Fig. 5b). Other coarse beds, however, display no lithic mode (ATO110, ATO126, Fig.

178 5a). If those beds were the product of a single mechanism, there should be large amounts of

179 lithics with a size depending of the specific mechanism. If, however, several processes occur

180 simultaneously, shear- and collision-induced rolling could reinforce the sorting of clasts

181 deposited by the other processes by remobilizing smaller grains of all densities, mixing them as a

182 result of size-dominated sorting. In this case, coarse pumices would naturally concentrate

183 because they are the largest clasts available.

184 At the transition between massive and stratified deposit, the absence of density sorting of

185 coarse, well-sorted layers (ATO128, Fig. 5a) suggests that airborne transport played a negligible

186 role in producing the transition. This is consistent with vanishing bed-load transport, where

187 particle collisions become less frequent and rolling becomes a prevailing mode of transport as

188 the depositional boundary layer evolves from dense to dilute.

189 Our findings are consistent with a depositional system forming a "traction carpet" (Sohn,

190 1997) that is composed of rolling and possibly saltating particles, upon which variable amounts

191 of suspended load falls from the transport system. We propose that shear- and collision-induced

192 rolling cause clasts to segregate by size and forms moving sheets of a few particle diameters

193 thick. Assuming that the width of planar beds are on the same order as their measured length

194 (Fig. 3), sheets are a few square decimeters, with those dimensions increasing to square meters

195 with particle coarsening. The good sorting of most horizontal planar beds suggests those sheets 
196 did not interpenetrate, but rather came to rest by stacking, forming the stratified beds. Sheet

197 truncation occurs if the substratum (usually previously deposited sheets) is irregular. The

198 absence of extensive pumice rounding indicates the sheets transported clasts over short distances,

199 most likely less than hundreds of meters. Similar bedload sheets have been observed in river

200 sedimentation (Whiting et al., 1988).

201 The absence of hydraulic equivalences for some well-sorted, coarse-grained beds

202 suggests they could be composed of clasts traveling through both the transport system and the

203 traction bed. It is doubtful that only rolling produced such beds, because conditions are not likely

204 to evolve from dense to dilute just before deposition, as would be implied by clasts rolling under

205 packed conditions before being deposited by shear- or collision-induced rolling. We propose

206 instead that such beds are the lighter remnants of the sorting operated within the large-scale

207 transport system (i.e., suspended-load fallout), whereas boundary layer processes (i.e., traction

208 carpet) control the sorting of other beds. Clasts coming from suspended-load fallout give crucial

209 parameters about the transport system, such as carrying capacity, or eddy size and speed

210 (Burgisser and Bergantz, 2002). To identify such clast populations, we suggest a strategy of

211 sampling stratified deposits at the outcrop scale (deposit thickness and $\sim 10$ times as much

212 horizontally) including selective sampling of the coarsest beds rich in lighter components.

213 Although less accurate, the largest mode of bulk samples may also be used because it often

214 corresponds to such coarse beds (Fig. 4).

215 Some pyroclastic deposits feature progressive distributions of wavelength of dune-forms

216 with distance from source (Sigurdsson et al., 1987). Stratified deposits in the UTP are not

217 progressively distributed, which might have resulted from the short distance over which these

218 deposits occur. Each of the two pulses composing $F_{1}$ produced a full spectrum of stratified 
219 deposits with low bed angle, self-similar planar beds and dunes, coarse pumice-rich beds, and

220 finer, well-sorted beds. All these characteristics are shared by many stratified deposits (Fig. 3;

221 Cas and Wright, 1987). The fact that such a small flow can generate most of the features

222 displayed in ignimbrites orders of magnitude more voluminous suggests the sequence of

223 mechanisms presented herein may operate elsewhere than Toluca.

224 By helping to discriminate between various transport mechanisms, hydraulic

225 equivalences have a general applicability in cases where the origin of deposit is uncertain, such

226 as Aeolian reworking of pyroclastic material (Smith and Katzman, 1991), hybrid fall layers

227 (Wilson and Hildreth, 1998), or coeval fall and surge (Valentine and Giannetti, 1995).

228 Furthermore, equivalences may be extended to other transport mechanisms, such as gravity grain

229 flow, as well as to other geophysical flows where clasts of contrasted densities are involved.

230 ACKNOWLEDGMENTS

231 We would like to thank J.-L. Macìs for introducing us to Nevado de Toluca, and J.-

232 L. Arce and K. Cervantes for their help in the field. AB also thanks J.-L. Bourdier for

233 stimulating discussions. We thank G. Valentine, Y.K. Sohn, H.D. Granados, L. Capra, and an

234 anonymous reviewer for reviews. Funding was provided by NSF grant EAR-0309703.

\section{REFERENCES CITED}

236 Arce, J.L., Macia, J.L., and Vazquez-Selem, L., 2003, The 10.5 ka Plinian eruption of Nevado de

237 Toluca volcano, Mexico: Stratigraphy and hazard implications: Geological Society of

238 America Bulletin, v. 115, p. 230-248.

239 Arce, J.L., 2003, Condiciones pre-eruptivas y Evolución de la Erupción Pliniana Pómez Toluca

240 Superior, Volcán Nevado de Toluca [PhD thesis]: Universidad Nacional Autonoma de

241 Mexico, 136 p. 
242 Burgisser, A., and Bergantz, G.W., 2002, Reconciling pyroclastic flow and surge: The

243 multiphase physics of pyroclastic density currents: Earth and Planetary Science Letters,

244 v. 202, p. $405-418$.

245 Cagnoli, B., and Manga, M., 2003, Pumice-pumice collisions and the effect of the impact angle:

246 Geophysical Research Letters, v. 30, p. 1636.

247 Cas, R.A.F., and Wright, J.V., 1987, Volcanic successions: Modern and ancient: London, Allen 248 \& Unwin, $528 \mathrm{p}$.

249 Chau, K.T., Wong, R.H.C., and Wu, J.J., 2002, Coefficient of restitution and rotational motions 250 of rockfall impacts: International Journal of Rock Mechanics and Mining Sciences, v. 39, $251 \quad$ p. $69-77$.

252 Crowe, C., Sommerfeld, M., and Tsuji, Y., 1997, Multiphase flows with droplets and particles: 253 CRC Press, USA, 496 p.

254 Dippel, S., Batrouni, G.G., and Wolf, D.E., 1996, Collision-induced friction in the motion of a 255 single particle on a bumpy inclined line: Physical Review E, v. 54, p. 6845-6856.

256 Fisher, R.V., 1990, Transport and deposition of a pyroclastic surge across an area of high relief:

257 The 18 May 1980 eruption of Mount St. Helens, Washington: Geological Society of 258 America Bulletin, v. 102, p. 1038-1054.

259 Hanes, D.M., and Bowen, A.J., 1985, A granular-fluid model for steady intense bed-load 260 transport: Journal of Geophysical Research, v. 90, p. 9149-9158.

261 Schmeeckle, M.W., and Nelson, J.M., 2003, Direct numerical simulation of bedload transport 262 using a local, dynamic boundary condition: Sedimentology, v. 50, p. 279-301. 
263 Sigurdsson, H., Carey, S.N., and Fisher, R.V., 1987, The 1982 eruptions of El Chichon volcano,

264 Mexico (3): Physical properties of pyroclastic surges: Bulletin of Volcanology, v. 49,

265 p. $467-488$.

266 Smith, G.A., and Katzman, D., 1991, Discrimination of eolian and pyroclastic-surge processes in

267 the generation of cross-bedded tuffs, Jemez Mountains volcanic field, New Mexico:

268 Geology, v. 19, p. 465-468.

269 Sohn, Y.K., 1997, On traction-carpet sedimentation: Journal of Sedimentary Research, v. 67,

270 p. 502-509.

271 Valentine, G., 1987, Stratified flow in pyroclastic surges: Bulletin of Volcanology, v. 49, p. 616272630.

273 Valentine, G.A., and Giannetti, B., 1995, Single pyroclastic beds deposited by simultaneous 274 fallout and surge processes: Roccamonfina volcano, Italy: Journal of Volcanology and 275 Geothermal Research, v. 64, p. 129-137.

276 Whiting, P.J., Dietrich, W.E., Leopold, L.B., Drake, T.G., and Shreve, R.L., 1988, Bedload 277 sheets in heterogeneous sediment: Geology, v. 16, p. 105-108.

278 Wilson, C.J.N., and Hildreth, W., 1998, Hybrid fall deposits in the Bishop Tuff, California: A 279 novel pyroclastic depositional mechanism: Geology, v. 26, p. 7-10.

280 Wohletz, K.H., and Sheridan, M.F., 1979, A model of pyroclastic surge: Geological Society of 281 America Special Paper, v. 180, p. 177-194.

\section{FIGURE CAPTIONS}

283 Figure 1. Left: map of Nevado de Toluca, Mexico, showing the extent of pyroclastic density 284 current deposits (unit $\mathrm{F}_{1}$ of the Upper Toluca Pumice). The black area are massive deposits $285(>2 \mathrm{~m})$, the thick dotted line delimits stratified deposits $(>2 \mathrm{~m})$ and the dashed line shows the 
maximum extent of $F_{1}$. Thick line shows the road to the town of Tenango (star). Circles indicate thickness measurements, triangles refer to sample locations, and square locates section of Fig. 2. Right: stratigraphic profile of $F_{1}$ showing the main facies and representative grain size distributions [size (in $\left.\mathrm{mm})=2^{-\phi}\right]$. In valleys, massive facies thickens markedly and the basal contact of stratified facies is often erosional.

291 Figure 2. Sedimentological data at the downstream transition from massive to stratified deposits

292 (Basal unit). A) Sketch of the outcrop with sample location. B) Density sorting (as expressed 293 by the difference between pumice and lithics) between the massive facies (ATO130), a 294 poorly sorted planar bed (ATO129), and a coarse planar bed (ATO128, see also Fig. 5a). C) 295 Difference in grain size distribution.

296 Figure 3. Characteristic shape (length versus thickness) of planar beds and dunes. Straight lines 297 are power-law correlations. Coarse beds are gravels and fine beds are sand or finer. Gray area 298 covers the extent of dunes from other deposits (Taal, Laacher, El Chichon, Ubehebe, and 299 Bandelier; Sigurdsson et al., 1987).

300 Figure 4. Sedimentological data of the stratified facies at Toluca. Dotted lines are samples with a 301 dominant pumice-rich coarse mode (labels are sample numbers, see also Fig. 5a). A) Grain 302 size distribution of 11 bulk samples (gray area). Solid line is a representative sample showing 303 the polymodal nature of bulk stratified layers. B) Grain size distribution of 9 beds. Solid line 304 is a representative sample showing the unimodal nature of individual beds. C) Density 305 sorting of 20 samples (gray area).

Figure 5. A) Size distributions of pumice (thick lines) and lithics (thin lines) of 4 individual stratified beds and 1 fall deposit ( $\mathrm{PC}_{2}$, Arce et al., 2003) at Toluca. Pumice and lithic modes are indicated when present (thick and thin vertical lines, respectively). B) Hydraulic 
309 equivalences for fallout, saltation, and rolling (inset is conceptual sketch). For each

310 mechanism, lines relate lithic $\left(2500 \mathrm{~kg} \mathrm{~m}^{-3}\right)$ size to pumice [702 $\pm 114 \mathrm{~kg} \mathrm{~m}^{-3}(1 \sigma)$ Arce,

3112003 ] size. Short-dotted line applies to falling/saltating clasts (Equ. 1) and packed rolling

312 (Equ. 8); solid line applies to shear-induced rolling (Equ. 8); long-dotted line applies to

313 collision-induced rolling (Equ. 10). Gray areas are ranges of equivalences caused by the

314 spread in UTP densities. Symbols indicate observed ratios for samples in A): samples

315 deposited by rolling (triangles), by fallout (open star), and by fallout/saltation followed by

316 rolling (squares). Errors not shown are smaller than symbols. 

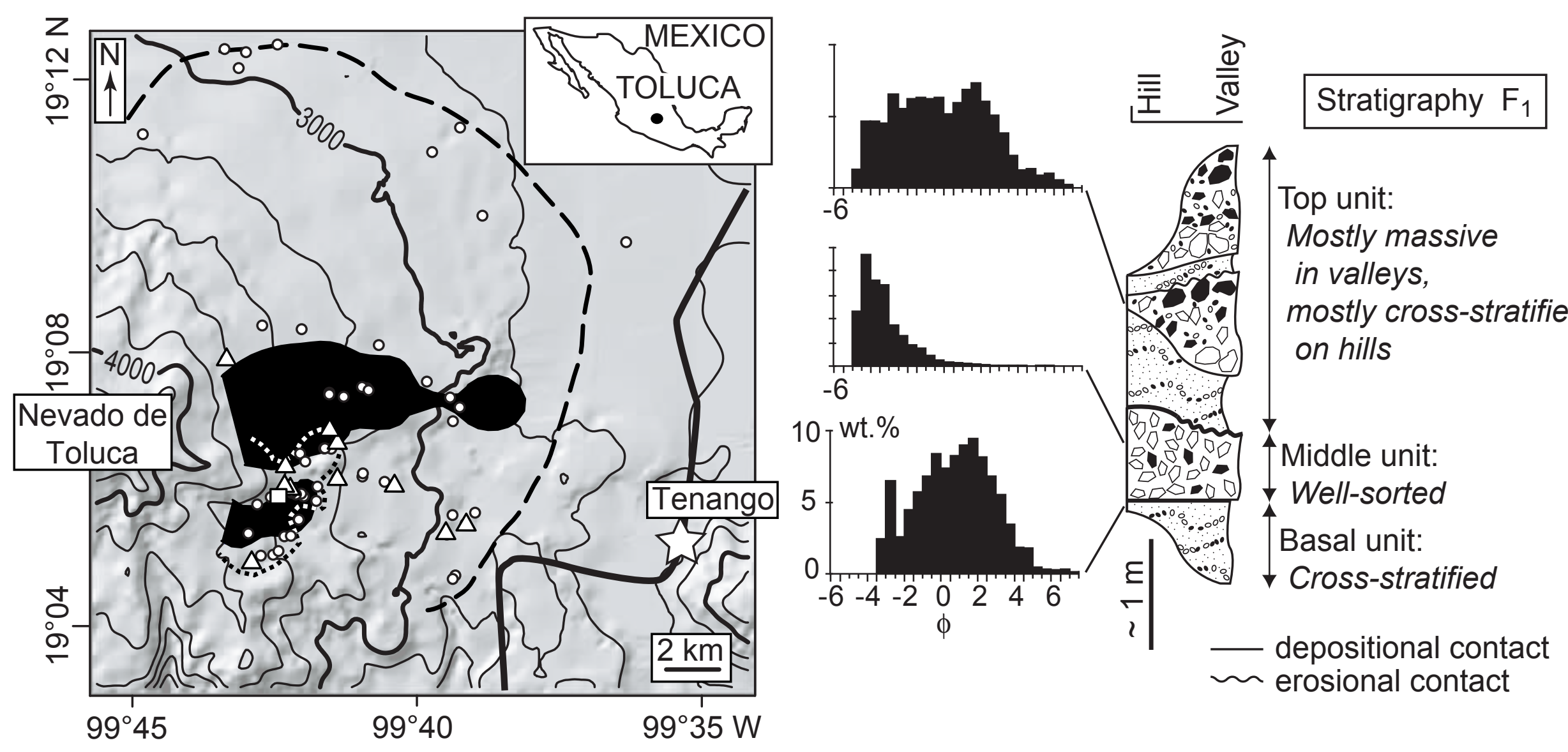
in valleys, mostly cross-stratified on hills

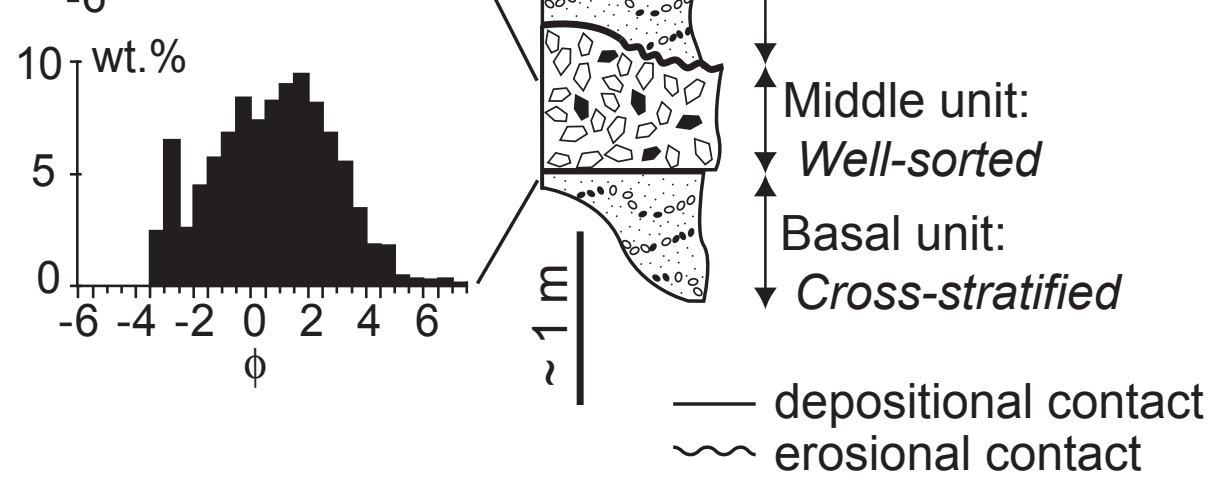

FIGURE 1 

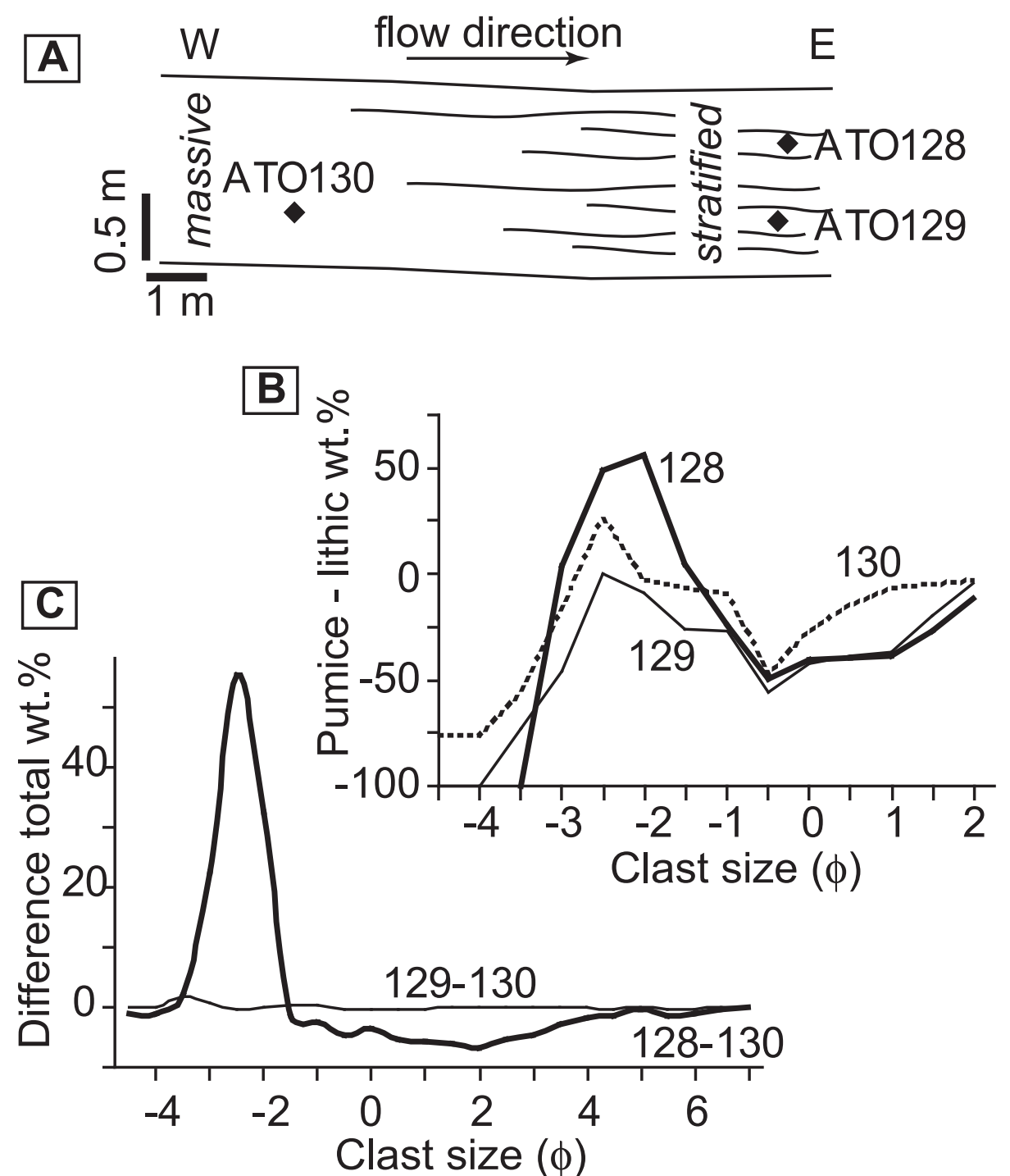


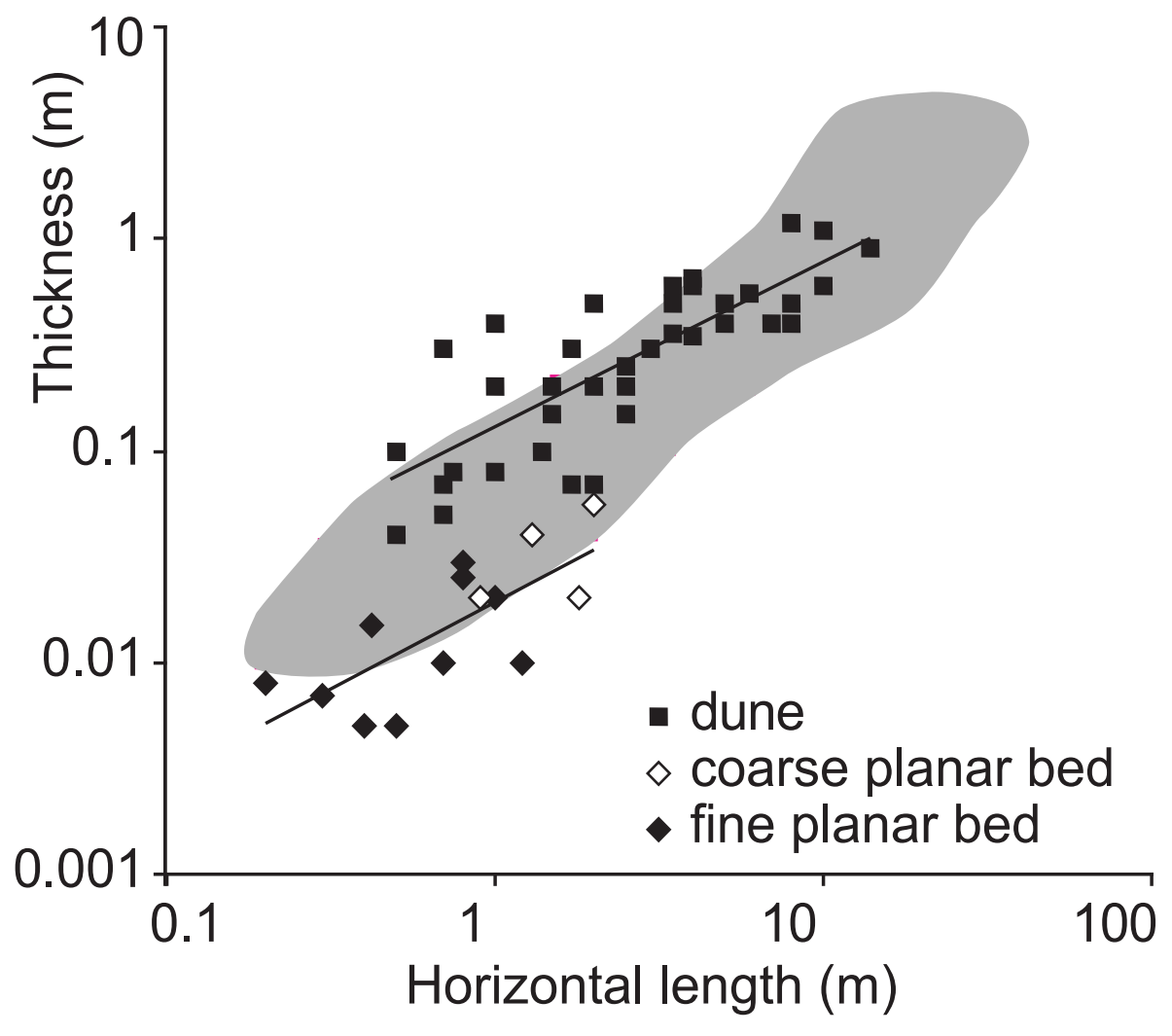

FIGURE 3 


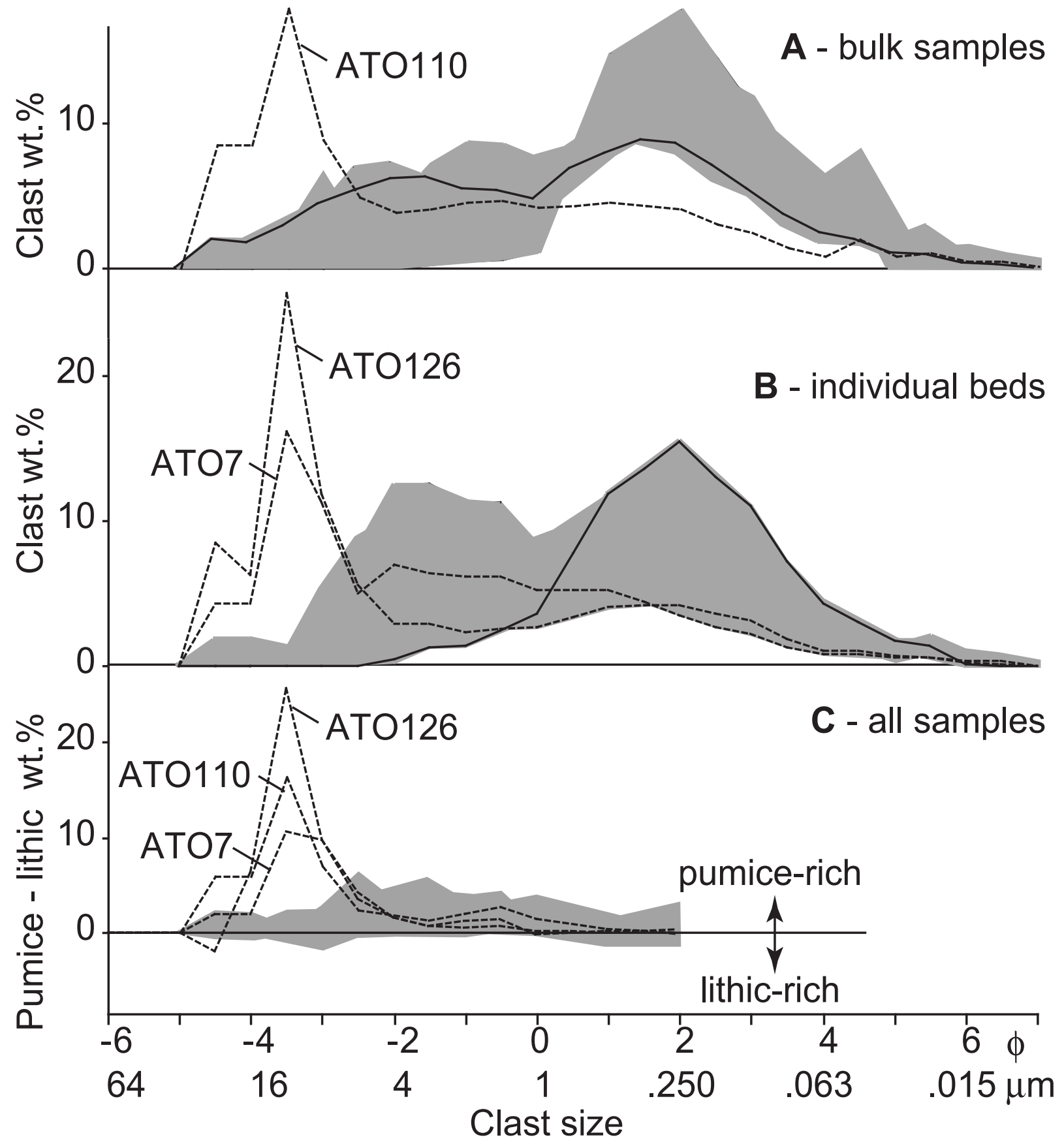

FIGURE 4 


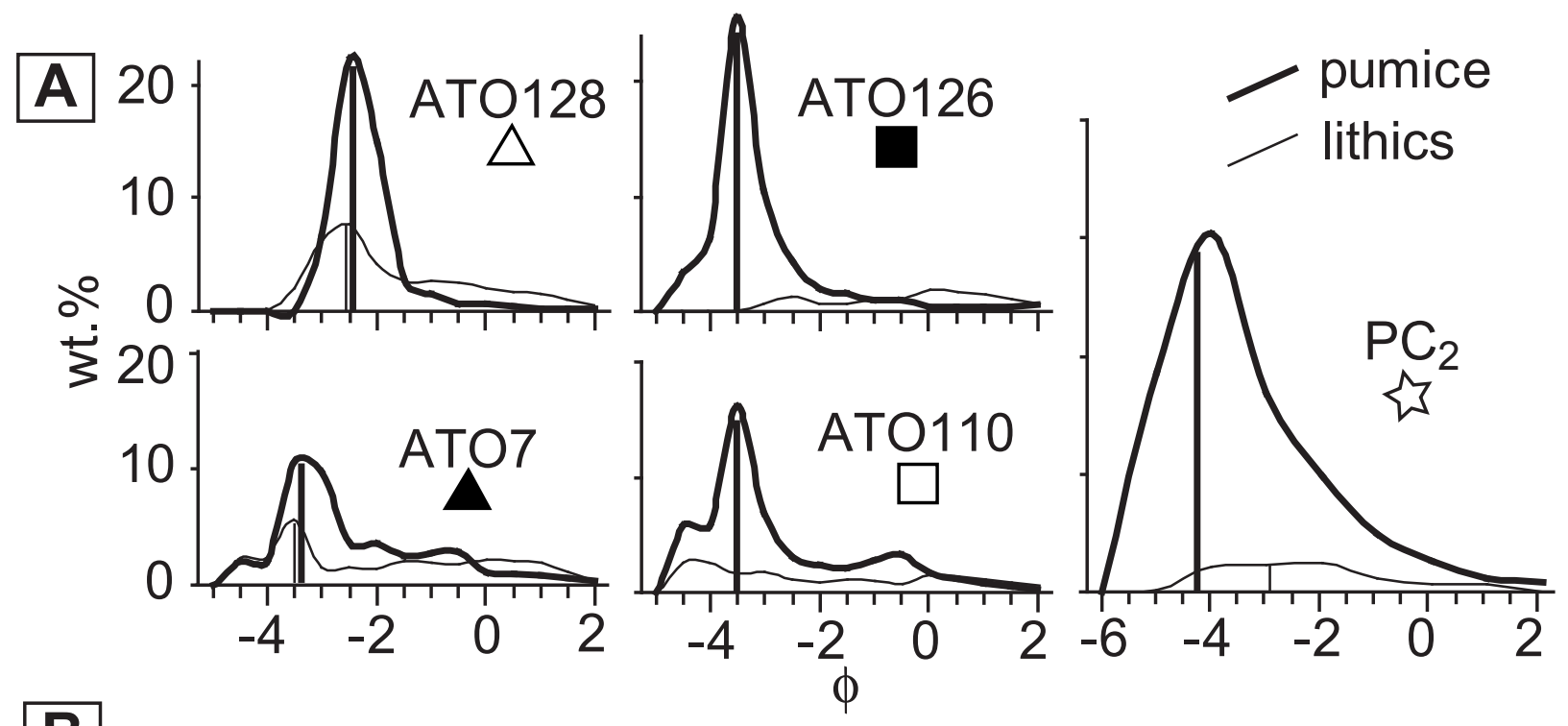

B

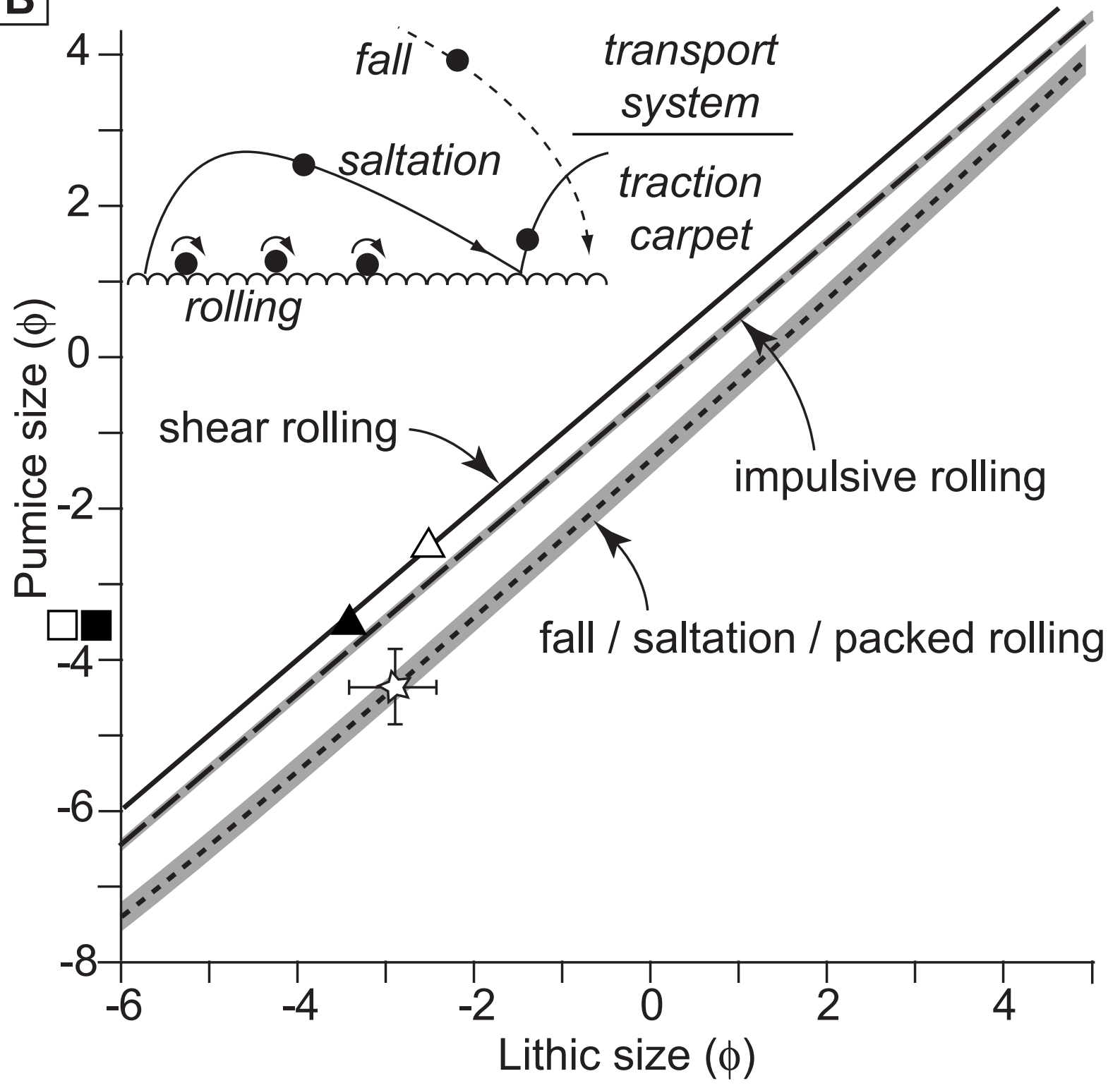

